\title{
Building Yingkou port into a main port in China
}

\author{
Zhen'an District Urban Construction Bureau of Dandong
}

\section{Introduction}

In terms of the geological location of Yingkou port, it gains support mainly from those cities in central Liaoning province, being the nearest marine outfall and the second open port among the three provinces (Liaoning, Jilin and Heilongjiang) in northeast. Yingkou port has formed a complete structure composed by the old port area, Bayuquan port area and Xianren island port. The long coastal line offers huge developing potential. Convenient transportation and the adjacency of several countries in the northeastern part also provide certain advantages for Yingkou port in the transportation of goods and containers.

Located in the southwest of Liaodong peninsula, Yingkou port lies near to the extensive backland of northeast and the east of Inner Mongolia, which makes it the heartland of northeastern Asia in international logistics and international gangway for transshipment. Being an important sound deepwater port in the north of China, the port outstands in location advantage, as it lies in the junction point of Bohai economic rim and northeastern economic area. Regarding its distance to the three provinces, it's $741 \mathrm{~km}$ from Yingkou to Harbin, the provincial capital of Heilongjiang, 499km to Changchun, Jilin, making Yingkou port the nearest estuary to the three northeastern provinces and four league hinterlands in Inner Mongolia. The cost disparity of continental carriage is comparatively obvious for shipping goods via ocean from short distance. Because Yingkou port is the nearest one to cities in central Liaoning, with all radius within $250 \mathrm{~km}$, it's the most reasonable shipping distance. Moreover, it's the nearest estuary for the three northeastern provinces and hinterland in Inner Mongolia, by $180 \mathrm{~km}$ compared with Dalian port. Compared with continental carriage, the cost nearly lowered by 10-20 RMB per ton. Thus, it can save vast logistics costs and shipping time for customers.

Yingkou port is one of our country's main ports of hub in coastal areas, as well as the nearest estuary in the northeast. With the continuing development of its production and construction, its open port has been expanding with each passing day. And the development of its open port also has extremely prompted the developments of import-export trade and domestic trade, has driven the development of modern logistics, harbor industries and so on. Recent years have seen a sound rise of business operations, especially the world-watching construction and development of Yingkou port------its open port has been expanding in scale, its functions perfected, its cargo handling capacity has been stably increasing and surpassed one hundred million tons in October 2007, making it the tenth of that ton level in China. According to statistics collected till November 2012, Yingkou port's cargo handling capacity has reached 277.53 million tons. Building it into a regional but modern international and powerful port with multi-functions not only helps the economic developments of three northeastern provinces but also a inevitable choice for China to blend into northeastern Asian economic circle and to gain more initiative in northeastern Asian economic cooperation.

\begin{abstract}
Harbor plays a pivotal role in the economic development of a country or an area. After the World War II, the recovery of Japan's economy, the emergence of "the Four Asian Tigers" and rise of China's coastal districts, including the Pearl River Delta and the Yangtze River Delta fully demonstrated harbor's strategic role in economic development. As the nearest port to ocean in northeastern area, port of Yingkou values a lot to the development of city groups in the central part of Liaoning province and economic districts in Shenyang province, as well, to the rejuvenation of old industrial bases in northeastern area. At present, port of Yingkou has achieved leapfrog development, becoming a big port of hub accommodating hundreds million tons of goods. And it also transforming its developing model----from a port of hub to a powerful international port which is modern service oriented. So, from new starting point, it is very timely and necessary to have a scientific and new outlook on and to carry out new research on its transformation and development of Yingkou port. This paper, by analyzing the back-land of Yingkou port, investigating its collecting and distributing system, as well as studying its informatization of the management of port and supports from government and politics, tries to make Yingkou port an important port of China.
\end{abstract}

Key words: Yingkou; harbor; WTO

Published online: 15th July, 2017 


\section{The status quo of Yingkou port's} development

Main features of cargo handling capacity of Yingkou port and Bayuquan port in recent years are as below:

(1) The cargo handling capacity keeps increasing with high speed. The average rate of increase was $37.2 \%$ during the "eighth five-year plan", breaking records made by nationwide ports' developments. And the rate kept increasing by double-digit during "the ninth and the tenth five-year plans". The constructions of Bayuquan port and deepwater berth greatly met the needs of economic development in hinterland as well.

(2) Featured by transfer transportation of large bulk cargo and transportation by sea of bulk cargo. Among the category of goods handled in the port, there were mainly coal, oil, metallic ore, non-metallic ore, chemical fertilizer and food, and the goods capacity handled accounted for $60 \%$ in the total cargo capacity handled in the port.

(3) Supply of goods came from the three northeastern provinces and three leagues and one city in eastern Inner Mongolia. Among each year's cargo capacity handled, supply of goods from Liaoning toke more than $70 \%$, with the most from Shenyang economic circle.

(4) The capacities of container, steel, metallic ore and coal increased stably. In 2005, the total cargo handling capacity was 75.37 million tons, and compared with that in 2000 , the average annual rate of increase was $27.2 \%$, among which the average annual rate of increase of container was $38.06 \%$, steel $33.5 \%$, metallic ore $45.88 \%$ and coal $31.07 \%$.

\section{Analysis of the cargo handling ca- pacity of main goods}

(1) Coal: Coal was a kind of goods fluctuated quite high in cargo handling capacity in the port. It stepped out the lingering situation in recent years and achieved large increase for two consecutive years, reaching 1.335 million tons in 2008. In future, the increase of coal's handling capacity will mainly come from three parts: first, the production put into of the second and third phase of Yingkou Huaneng power plant will ensue coal imported increase doubled; second, coal imported by various enterprises in hinterland, particularly Anshan Iron and Steel Group Corporation Yingkou steel mill, will increase; third, striving for enterprises like Huaneng Group that exploit coal in eastern Mongolia to choose Yingkou port as the port to launch. It is forecasted that the coal handling capacities of Yingkou port in 2010, 2015 and 2020 will be 27 million tons, 51 million tons and 110 million tons respectively.

(2) oil and its products: in recent years, oil's handling capacity was around 5 million tons, reaching 5.924 million tons in 2008. After 300000 tonnes crude oil was put into production in Xianren island port, it values a lot. Besides crude oil which has been identified to be imported for Huajin Group and heavy rubber asphalt unloading project in energy and chemical industrial area in Xianren island port, it will definitely have important influences on the construction of petrochemical industry parks in port-nearing area in Xianren island and Shenyang, as well as on the transport pattern of crude oil in the northeast. It also may make it possible to have Fushun petrochemical settle down its reserve warehouse of imported oil, strategic or business crude oil here in Xianren island. The development of port-surrounding oil processing industry will definitely trigger the need of transporting refined oil products and liquid chemicals. It is estimated that the industrial agglomeration effect of port-surrounding petrochemical industry park and the transport cluster effect of oil and its products in Xianren island port will appear recently. And according to estimation, the oil and its products handling capacities of Yingkou port in 2010, 2015 and 2020 will be 20 million tons, 36 million tons and 67 million tons respectively.

(3) Metallic ore: it's one of those goods which increased the most rapidly in Yingkou port in recent years, with28.874 million tons handling capacity in 2008. In future, the in- creased capacity of metallic ore transported will mainly come from Anshan Iron and Steel Group Corporation Yingkou steel plant, whose total steel output will reach 5.5 million tons and 11 million tons respectively and quantity of imported iron ore acquired will be about 8 million tons and 16 million tons respectively after its second and third phase of constructions are put into production. As Yingkou middle plate plant and Yingkou five mines increased their metallic ore, the metallic ore handling capacities of Yingkou port in 2010, 2015 and 2020, according to estimation, will reach 35 million tons and 50 million tons and 50 million tons respectively.

(4) Steel: it's one growth point of cargo handling capacity in Yingkou port in recent years, with 19.785 million tons in 2008. In future, total steel transport quantity increased will be also mainly from Anshan Iron and Steel Group Corporation Yingkou steel plant which will set its own wharf to transport, making Yingkou port's cargo handling capacity growth slows down evidently. It is estimated that the steel handling capacity of all ports in Yingkou port in 2010, 2015 and 2020 will be 25 million tons, 31 million tons and 36 million tons, among which the handling capacity of Yingkou port itself will maintain at about 25-26 million tons.

(5) Food: it's handling capacity in recent years remains at 5 million tons, reaching 4.048 million tons in 2008. With the implementation of our country's project of increasing grain production by hundred billion kilograms, great growths have been seen in the export quantities of corn and rice produced in the northeast. It is estimated that the grain handling capacity in Yingkou port in 2010, 2015 and 2020 will reach 7 million tons, 10 million tons and 12 million tons respectively.

(6) Container: it's always the most important growth point in cargo handling capacity, with 2.0364 million TEU in 2008. Yingkou port has become a transportation junction of containers from domestic trade, obvious in agglomeration effect. Economy in hinterland will keep growing 
and Shenyang economic circle will become a hot land for investment. Ministry of railways is making great efforts to facilitate container transportation. Cargos in hinterland in depth transported with the combination of railway and waterway containers, which effectively reduced the cost. With the transportation scale of foreign trade containers in Yingkou port gradually formed and the improving of comprehensive conditions in port, the handling capacity of foreign trade containers will also form a virtuous cycle. It is estimated that the container handling capacity of Yingkou port in 2010, 2015 and 2020 will reach 3 million TEU, 5 million TEU and 8 million TEU, respectively.

Measures can be taken to build Yingkou port into a main Chinese port:

\section{Making the most of the adv - tages of Yingkou port itself}

\subsection{Taking full use of the powerful support from hinterland}

The direct support of Yingkou port is from Yingkou city, and its direct hinterland is centering on Shenyang economic circle, and its indirect hinterlands consist Liaoning, Jilin, Heilongjiang provinces and three cities plus one league in northeastern Inner Mongolia. Thus, Yingkou port has been set by Liaoning province as a seaport modeling by " $6+1$ " in Shenyang economic region. Relying on northeastern economic region, Yingkou port mainly transports large bulk cargo, and goods it can collect and distribute are container, metallic ore, nonmetallic ore, grain (grain in bag and bulk grain), coal, steel, lumber, petroleum coke and roll-on/rolloff car.

\subsection{Taking advantage of perfect collecting and distributing system}

Yingkou port is convenient in transportation. Shenyang-Dalian expressway and Harbin-Dalian highway lie along the port, Changchun-Dalian railway reaches the wharf apron, and container regular trains from Yingkou port to Changchun, Dehui, Harbin, Gongzhuling, Siping and Songyuan as well as international container special trains passing Manzhouli to
Europe have been opened. Container marine lines have covered main ports in coastal areas, several international marine lines to countries and regions like Japan and Korea and several domestic marine lines which can be transfers to places around the world also opened. As a result, Yingkou port has set up carrying trades with over 140 ports in more 50 countries and regions. Yingkou port has special ports equipments to reserve various refined oil and petrochemical products. Moreover, its special oil transmission pipelines can through to Liaohe oilfield and Fushun petrochemical, realizing vertical crossing operation simultaneously of pipeline, seaway, railway and expressway.

\subsection{Building a informationalized port management system}

The fast speed development of Yingkou port can't be separated from the great support of informatization. The dynamics of information in port is strong and sharing. Mastering of those production information timely and correctly can not only improve the strain capacity of port management to gain initiative in market competition but also can offer consultancy service meanwhile for ministries of expressway, seaway, trade and port. In a word, informatization has made important contribution to the port's plan to proceed to ports which can accommodate hundred billion tons cargos.

\subsection{Taking full advantage of capital}

The joint stock company was set up after the reform and recombination of Yingkou port. It operates strictly abiding by modern enterprise system and perfects its legal person management structure. Since it went into public in 2002, Yingkou port's share price has been powerful in momentum, being considered as blue chip all the time, which offered a financial guarantee for the construction of international port and for the investment to infrastructure in the port.

2. Makin comprehensive use of external conditions for the development of Yingkou port

2.1 Utilizing good policies issued by the government
With the continuous deepening of the "Great revitalization of the northeast" strategy and the economic recovery of old industrial bases in the northeast, Yingkou port has met a bigger opportunity to develop. In 2003, Yingkou city established " the project to revitalize old industrial bases" and the municipal committee and government proposed sparing no efforts to build "one platform, three bases and five industries": taking building a good port as platform, building modern logistics base which serve the northeast, leading light and textile industries base in Liaoning, a industrialization base of national magnesian material, and developing five industries that are metallurgy, petrochemical, equipment manufacturing, new type of building material and intensive processing of agricultural and sideline products. We should make full use of the agglomeration and radiation effects of port to develop Yingkou coastal economic belt under the strategy of "striving cities with ports, striving cities with industries", gradually perfecting warehousing industry, expanding industry area, building business and dwelling complex and tourism areas. We also should further develop sea-boarding industries, warehousing and transportation, tourism, carrying trade and the system of export, production and processing, meanwhile, preferential local policies should be offered to support the development of Yingkou port.

On July 1, 2009, The Development Plan of Liaoning Coastal Economic Belt was passed on executive meeting of the State Council. By then, Liaoning coast was incorporated into national strategy as integrated development region. This plan regarded "the five points and one line economic belt" raised by Liaoning as its core, and expanded the scope of the original one. According to the property of Yingkou port and national policies' instruction, Yingkou port in the future will have multiple modes of transportation, including waterway, highway, railway and pipeline. As a service system, is can integrate port enterprises, logistics enterprises and sea-boarding industries very well. Besides those mentioned above, 
Yingkou port also can perform functions like port-surrounding industries, communication information, comprehensive service, tariff guarantee, processing, commerce and trade, and tourism.

The construction of Yingkou port needs great supports from Yingkou city, Liaoning province and even the government. The completion of cargos' operation in port not only calls for port authority's but also port enterprises' unremitting efforts. Meanwhile, it also calls for close coordination from vessel operators, cargo agencies, highway transportation enterprises, inland water transport enterprises and relevant departments in the government (like customs, border defense, commodity inspection and flora and fauna investigation). Besides that, governments in various levels also should offer necessary supports to Yingkou port in infrastructure construction, land removal and relocation compensation and so on.

\subsection{Taking advantage of the entry into WTO, we can build Yingkou port into a main port in China}

$\square \square$ Since the reform and opening up, the value of import and export has been on the rise annually, which makes hinterland in Yingkou port got a certain development in foreign trade. After the entry into WTO, the growth of our country's volume of import and export ensued a great increase in seaborne volume of foreign trade, bring sufficient supply of goods and sound trading opportunity for the development of Yingkou port and facilitating corporations' further use of foreign capitals to speed up in making progress in technology and to improve management level.

After the entry into WTO, the trend of world economic integration became more and more obvious. From the perspective of international and domestic economies, international trade will gain raise in more extensive fields. As a frontier of a country or a region to integrate with the world market and to participate in world economy recycle and to launch international trade, port is undoubtedly an important channel to bring in new ideology, to strengthen exchange of international information, to cultivate and perfect market economy.

Particularly, the functions that modern ports have like commerce, industry, business and transportation will further expand and deepen port's influence in the development of industrial economy. Yingkou port, as a port mainly runs international trade (foreign trade accounts for $80 \%$ ), as well a developing port which is stepping into the rank of large modern ports, is perfecting its functions and developing its port-surrounding industries, posing an important function on promoting the restructuring of industries in the northeast.

\section{Making up for its own deficiency to prompt the all-dimensional de- velopment of Yingkou port}

\subsection{Improving its handling capaci- ty by strengthening infrastructure construction of the port}

In terms of transportation of the port, the greater the tonnage of freighter is, the cheaper the charge is. So, to make Yingkou port a powerful modern hub port, the construction and transformation of large specialized bulk cargo port in Yingkou port have to be accelerated, strengthening port handling capacity and shortening dwell time of cargos in port. Besides, constructions of infrastructure in port like the number of containers in port, handling capacity, storage yards in port and fairway depth have to be strengthened to provide large modern warehouse for logistics service suppliers and to create "zero storage" for customers.

Handling capacity and scale are the most basic index demonstrating that port is becoming powerful. In 2003, Yingkou port came up with the target of constructing port that can accommodate hundred billion tons cargos, and by 2010 , its handling capacity will reach one 100 million tons, the number of containers will reach 1.6-2 million TEU, which calls foe a further expanding of Yingkou port in scale. In the following development and construction, Yingkou port needs to construct 5000 thousand tons deepwater berths requested by con- tainer, steel and sundries. Moreover, to make it further perfected in main functions, and ultimately achieve leapfrog development, Yingkou port needs to build ten-thousand tons refined oil, build deepwater berths for vessels that accommodate liquid chemical, transform existing berths to make them hold more vessels, gradually build new grain silos, extend highway for port, implement the construction of modern logistics industry parks and EDI.

\subsection{To further perfect collecting and distributing conditions}

To make Yingkou port a powerful modern hub port, the needs of industrial distribution and transportation in radiated regions have to be taken into consideration. In recent years, the container transportation in Yingkou port has entered the fast traffic lane of leapfrog development, and domestic trade lines have covered all ports in China's coastal areas, becoming the second largest port for container transportation of domestic trade. In future, while keeping developing near-sea shipping lines to Japan and Korea, we should open ocean lines to South Asia, North America and Europe and speed up the development of container transportation according to international enterprises' needs. In other words, taking advantage of the opportunity to build old industrial bases in the northeast, we should further perfect the inland collecting and distributing network of Yingkou port.

\subsection{Speeding up the process the in- formatization of Yingkou port and improving its service efficiency}

To promote the process of Yingkou port's informatization can, on one side, offer a theme for and set up data warehouse accordingly to categorize customers, thus different measures can be taken to different customers; on the other side, informatization can be updated again in 2009 and various management systems can be set up to make high level management in Yingkou port more effective. Based on advanced ideology and resources, meanwhile, bonded warehouse and tariff-free area should be built and the sphere of free activities of cargos should be expanded to make cargos 
can be freely transported, stored, exchanged, dealt and simply processed and packed in prescribed scope. Tariff-free treatment should be available to realize the four functions of international transfer, international delivery, international purchasing and international carrying trade, attracting more ship-owning companies and large-scale enterprises.

\subsection{Developing harbor industries reasonably}

The development of harbor industries in Yingkou port should be operated according to the requests of scientific outlook on development. We should coordinate developments between port and coast areas, coastal areas and hinterland, harbor industries and new types of industries, perfect industrial planning, regulate industrial distribution and optimize industrial structure. We should accelerate the construction of Yingkou coast economic belt which is headed by port, centering on industrial bases in Liaoning and supported by economic and technological development zone in Yingkou, high teach industrial park, energy and chemical parks in Xianren island and other various coastal parks. We should also strive to develop six new industrial cluster, namely metallurgy, petrochemical, equipment manufacturing, magnesian materials, new types of building material and textile and garment. At the same time, we should strengthen the supply ability of production factors, create sound environment for industrial development and make reasonable arrangements for the use of construction land for key projects of heavy chemical industries in port.

Local governments should actively lay out and construct coastal industrial parks, enact flexible and loose preferential policies, encourage bring-in projects, reduce or free charges for land leasing, planning and construction and taxation, thus forming a competitive policy atmosphere. We should set up talent introduction and cultivation mechanism and give priority to develop road traffic construction in port area. To develop port oriented industries should make full use of regional, port and resource advantages; to develop harbor industries needs to have a good connection with economic structure in Yingkou city, focusing on export-oriented industries; connection with economy in hinterland should be set up to serve the revitalization of old industrial industries in the northeast; so does connection with logistics to give play to the function of collecting and distributing pivot.

\subsection{Expanding functions of the port and striving to develop logistics in port-surrounding areas}

At present the development of logistics in Yingkou port lacks necessary competitive strength, investments in logistics value-added services like distributing processing, message service, inventory management and cost control, particularly in the design of logistics project and whole course of logistics service. In terms of logistics system, Yingkou port is centering on port district and gain support from economy area within radiation of the port, so we can adopt the development model of "port-surrounding logistics parks-logistics center-distribution center" to build a system of layers of regional logistics points. Yingkou port can form a strategic alliance relation with relevant ports (like Dalian port and Jinzhou port), so we can support and develop a batch of logistics enterprises, logistics parks and distribution centers which have economic strengths, operate according to international practices and have reasonable network structures, accelerating the construction of logistics networks.

To develop modern logistics in port is good for expanding the port's handling capacity via cargo's cluster effect, increasing the additional value of port service and comprehensively improving the port's competitive power. Now Yingkou port has put 2 million RMB on logistics parks to facilitate the exploitation and development of international logistics parks like Xianren island. Building international logistics parks in Xianren island into a green passageway for international import and export, and cultivating markets of chemical fertilizer, steel, grain and mineral powder and distributing center to promote the spawning of material flow, information flow and capital flow in Liaoning and old industrial bases in the northeast and to accelerate the development of modern logistics by participating in the planning of logistics system in city groups in central Liaoning province.

\section{6 carrying out the strategic co- operation of port and shipping to raise the port's competitive power}

We should maintain a good relation between port and city and implement the strategy of "striving city by port".

With the acceleration of globalization and the process of market integration, the cooperation of port and shipping has become a basic strategy foe the port's development. At present competition between Yingkou port and its surrounding ports are fierce, as all ports are striving for developments and making their service and market status gain great improvements. Many main ports domestically and abroad are making every endeavor to build strategic and cooperative partnerships with transnational shipping enterprises or groups to outstand in fierce competitions among ports.

At present, Yingkou port has made itself one of the top ten large ports in China, and its role in the revitalization of old industrial bases in the northeast and the construction of ports nationwide also increasingly obvious. To make Yingkou a major international port and distributing center in the northeastern part of China, as well a modern port city advanced in economy and technology in the northeast, the strategy of "striving city by port" still needs to be implemented in Yingkou, as well a good performance in the planning of "one city and two ports". We should also, according to the principle of consolidating, improving, exploiting and developing new ports, accelerate the three phases construction of port to make Bayuquan become a real port with world-level deepwater wharf. Yingkou should give full play to two-way radiation and the functions of "window" of the port, thus facilitating the development of Yingkou's economy, give full play to the industrial function of the port to driven harbor economy, and give full play to the city function in port areas to promote the construction of infrastructure. 
4.Utilizing contents in project managements to analyze the theory of reasonable transportation of hinterland-port logistics

As an important point in logistics chain, port chosen matters a lot to the cost of cargos. However, when a hinterland faces multiple available ports, it's pivotal to choose a best logistics route to transport. Theory about that has nearly matured. Because transportation is one of the most important functional factor, rationalization of hinterland-port logistics largely relies on the rationalization of transportation. And logistics transportation is the result of interactions among various economic, technological and social elements, factors affect the rationalization of transportation are quite a lot. And factors from five parts that act decisively are called the "five factors" in the rational transportation of hinterland- port logistics.

\section{Shipment distance.}

For transportation, several technological economic index like time, damage of cargo, freight and circulation of vehicles all have a certain relation of proportion with distance, so the length of transportation is the most basic element in evaluating the transportation is rational or not. So, when a enterprise is organizing the shipment of goods, the first consideration gives to the length of transportation, trying to make it optimized in transport route. In other words, the length of transportation is the most basic element in evaluating the transportation is rational or not, because shortening the distance of transportation can bring benefits from the macro or the micro. Conversely, it can bring damages to society, economy and logistics.

Each increase in the number of transportation will not only add the freight of start shipment and total freight, but also will definitely add affiliated activities to transportation, like load and unload and packing, various technological and economic index will decline therefore. So, reducing transport links, particularly the link of same transport facilities, prompts rational transportation.

Transport facilities.
All transport facilities have their own advantages. So the optimization selection of transportation facilities should be made according to features of different goods. We can use railway, waterway and automobile transport to select the best transport route to use transport capacity rationally, and use features of transport facilities to operate handling and transportation to optimize the function of transport facility utilized.

The time management of project is to guarantee the project can finish a series of management process on time. It includes the limitation of specific activity, such as the sequencing of activities, estimation of time, schedule development and time control.

\section{Managing of transport time in Yingk- ou port.}

Transportation is the link which consumes time quite a lot in the process of logistics, especially in long-distance transportation. In the total logistics time, transportation time accounts the most, so the shortening of transportation time plays a decisive role in the whole transportation time. Besides, short transportation time is beneficial for the quick turnover of transportation facilities, and making the most of the function of transport capacity is good for the turnover of cargo owners' capitals, as well, for the improvement of transportation routes' through abilities, making great contributions to the rationalization of transportation.

The cost management of project is to guarantee the actual cost and expense to complete a project can't exceed the management process's budget cost and expense, which consists works like the allocation of resources, the budgets of cost and expense and the control of expense.

\section{The transportation expenses in Yingkou port.}

Freight accounts for a large proportion in the total logistics expenses, so it, to a great degree, decides the whole logistics system's competitive power. In reality, the reduction of transportation expense is an important target, no matter to cargo owner enterprise or to logistics enterprise.
Judgment about freight is also one of the ultimate criteria to judge various rationalization implementation is effective or not.

Factors mentioned not only interrelated but also mutually contradicted. So, we need to conduct comprehensive analysis. Expected result can be achieved if we consider transportation rationalization from those five parts mentioned above. In practical application, it is the key to shorten transport time as much as possible and transport expense as less as possible in general case while considering rational transportation, this is because the two factors epitomize the economic efficiency in the process of logistics.

\section{Conclusion}

In the future, the development of Yingkou should follow the scientific outlook on development and requirements for the general port planning to construct a modern comprehensive port which integrate container warehouse, transfer and reloading, transport organization, modern logistics, harbor industries, communication and information, comprehensive service, tariff guarantee, processing, commerce and trade and tourism into one that is advanced in facility, perfect in function, efficient in management, remarkable in efficiency, harmonious in environmental protection.

\section{Reference}

[1] Current Chinese Economic Report Series, 2016.

[2] Coastal opening affects the interior of the province, Business Daily Update, Dec 32010.

[3] Wang. 9: Regional Integration Development in Central Liaoning Urban Agglomeration. Old Industrial Cities Seeking New Road of Industrialization, 2014.

[4] Gao, Wei, and Yan Zhang. A study of portvicinity industry cluster development of Liaoning coastal economic belt. 2012 2nd International Conference on Consumer Electronics Communications and Networks (CECNet), 2012. 